\title{
DEM RECONSTRUCTION OF LARSEN B REGION BASED ON 1960S OPTICAL SATELLITE IMAGERY
}

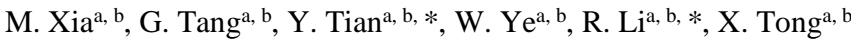 \\ ${ }^{a}$ College of Surveying and Geo-Informatics, Tongji University, 1239 Siping Road, Shanghai, China \\ ${ }^{\mathrm{b}}$ Center for Spatial Information Science and Sustainable Development, Tongji University, 1239 Siping Road, Shanghai, China \\ - (1994menglianxia, 1434919, tianyixiang, yewenkai1990, rli, xhtong)@ tongji.edu.cn
}

Commission VI, WG VI/4

KEY WORDS: Larsen B, DISP, DEM, Reconstruction

\begin{abstract}
:
Antarctica is an important part of the earth system and crucial to global sea-level and climate change. In 1995, a number of US intelligence satellite photographs from the1960s to 1970s have been declassified, only a portion of which (ARGON) covers the Antarctica. It provides a broader perspective to study the early Antarctica and it's very important for us to study the changes in the early stage of Antarctica. In this paper, a hierarchical stereo image matching strategy was used to reconstruct a digital elevation model of the Larsen B region of Antarctica Peninsula in 1960s using ARGON images. The accuracy of the matching result estimated in all layers is within one scanned-pixel of $33 \mathrm{~m}$ and the accuracy of geometric modelling after bundle adjustment estimated by using check points is within one nominal pixel of $140 \mathrm{~m}$. In the future, the elevation changes from 1960s of Larsen B tributary glaciers will be analysed.
\end{abstract}

\section{INTRODUCTION}

Antarctic Peninsula (AP) has undergone significant changes in the area of ice shelves, ice thickness, air temperature and et al. over the past few decades. Studies on AP shelf changes have shown that the regional environment changes can cause substantial losses in ice shelf (Cook and Vaughan, 2010). A lot of researches have been published about Antarctic Peninsula, especially Larsen B ice shelf. With the rise of regional climate in the past decades, accelerated retreat and break-up have been observed on Antarctic Peninsula ice shelf (Vaughan and Doake 1996, Skvarca et al., 1999, Rack and Rott, 2004). Skvarca et al. (1999) analysed 34 year satellite time series data from 1963 to 1995 suggested Larsen B lost $2320 \mathrm{~km}^{2}$ in area at the end of January 1995, Rack and Rott (2004) summerized the area of Larsen B ice shelf changes between 1995 and 2003, during that period the ice shelf area decreased from $11512 \mathrm{~km}^{2}$ to $2667 \mathrm{~km}^{2}$, only $2400 \mathrm{~km}^{2}$ remaining in 2009 (Cook and Vaughan, 2010). On eastern Antarctic Peninsula occurred two big collapses, Larsen A ice shelf in 1995 and Larsen B ice shelf in 2002. A new NASA study reveals that remnant Larsen B ice shelf likely to disintegrate completely by the end of the decade (Steve Cole and Alan Buis, 2015). Besides the area change, numerous studies focused on ice velocity and ice thickness changes are published. The largest tributaries of Scar Inlet ice shelf, Flask and Leppard glaciers, decrease rate 38\% and 46\% higher in 2013 than 1995 (Wuite et al., 2015). From 2000 to 2003, Hektoria, Green and Evans glaciers increased eightfold and declined since 2003; Jorum and Crane glaciers accelerated continuously from twofold in 2002 to threefold in 2003; on the contrast, farther south Flask and Leppard glaciers had no significant changes (Rignot et al., 2004). Khazendar et al. (2014) used RANDSAT-1 (1997, 2000, 2004), ALOS PALSAR (2006-2010) and TanDEM-X (2012) to obtain the velocity of Scar Inlet ice shelf. The result showed the ice flow speed accelerated from $475 \mathrm{~m} \mathrm{a}^{-1}$ to $750 \mathrm{~m} \mathrm{a}^{-1}$ during 2003 and 2013. From 1997 to 2012, Flask and Leppard glaciers increased by $55 \%$ and increased from $325 \mathrm{~m} \mathrm{a}^{-1}$ in 1997 to $400 \sim 500 \mathrm{~m} \mathrm{a}^{-1}$ in 2004. From 2006 to 2012, the acceleration rate reduced and speed was about $450 \mathrm{~m} \mathrm{a}^{-1}$ to $520 \mathrm{~m} \mathrm{a}^{-1}$. Shepherd et al. (2003) revealed that averaged surface decline trends of Larsen $\mathrm{B}$ ice shelf is $-0.17 \pm 0.11 \mathrm{~m} \mathrm{a}^{-1}$ during 1992 and 2001. After calculating the elevation change rates of six major glaciers of Antarctic Peninsula, Fricker and Laurie (2012) concluded that this area was lowering in average rate of $-0.03 \sim-0.16 \mathrm{~m} \mathrm{a}^{-1}$ thirty years after 1978 and average $\mathrm{dh} / \mathrm{dt}$ was about $-0.2 \mathrm{~m} \mathrm{a}^{-1}$ in six inter-mission crossovers from 1992 to 1997, two of which keep the rate of $\sim-0.19 \mathrm{~m} \mathrm{a}^{-1}$ during 1998 to 2008 . By employing the fluxes difference between the pre- and post-collapse, Rott et al. (2011) estimated the mass loss of Larsen B embayment, for example $4.34 \pm 1.64 \mathrm{Gt} \mathrm{a}^{-1}$ in 2008 . The combined mean loss rate of Larsen B tributary glaciers during 2001 to 2006 was estimated at least $11.2 \mathrm{Gt} \mathrm{a}^{-1}$ by tracking ice extent and elevation changes (Shuman et al, 2011). Berthier et al. (2012) evaluated the mass loss rate of Larsen B tributary glaciers was $\left(9.0 \pm 2.1 \mathrm{Gt} \mathrm{a}^{-1}\right)$ during 2006-2010, closing to the rate $\left(8.8 \pm 1.6 \mathrm{Gt} \mathrm{a}^{-1}\right)$ from March 2002 to 2006, derived using DEM differencing and laser altimetry.

There is very little data to estimate ice thickness and surface elevation changes before 1970s. The 1960s ARGON optical satellite images declassified in 1995 provide valuable historical data for studying the early changes in the Antarctica. In this paper, one pair of ARGON stereo images in the same track were used to reconstruct three-dimensional terrain of Larsen $\mathrm{B}$ region by hierarchical matching strategy. The study is important for revealing the elevation changes and mass balance of the area over half a century.

\section{METHODS}

This section focuses on the process of DEM establishing, including the epipolar images generation, the matching process 
and the bundle adjustment. The ARGON images used to establish the Larsen B DEM are DS09058A014MC115 and DS09058A014MC115.

\subsection{Epipolar Images Generation}

Matching based on epipolar images could reduce the search ranges in the following stereo image matching process. Since Helava (1972) proposed the concept of epipolar in 1970s, a lot of ways to establish the epipolar image were emerged. Here we used fundamental matrix calculated from a series of corresponding image points on two images to perform epipolar images. The steps of the epipolar images generation for the stereo image were discussed in details by Hartley and Zisserman (2003).

\subsection{The Matching Process}

Stereo image matching is one of the key techniques to establish the DEM. A novel method performed to estimation of terrain information and motion speeds from a stereo image pair simultaneous was proposed (Li et al. 2017), the matching strategy in this paper referred to this top-down hierarchical matching method. The study area is $6046 \times 5458$ pixel size at original image layer. In order to avoid the effects of tiny features and image noise, a five-layer Gaussian image pyramid was applied to epipolar images. The details of matching process were as follows.

1) In the 1st layer, SIFT (Lowe 1999) operator was used for feature detection and matching. In generally, the distribution of matching points is critical to sketching the outline of topography in the entire study area, so some points on the top of the mountains and the foot of the mountains was added manually (Figure 1).

2) The SIFT matching points and manual points were derived from step one as seed points (Row 1 and first layer in Table 1) to generate a triangulated irregular network in both images respectively, and then using Shi-Tomasi (Shi 1994) corner detector to detect the feature points (Row 2 in Table 1) in both images. According to the position of the feature point in the left triangulation, the position in the right triangulation is predicted according to the parallax of the three vertices of the left triangulation. Feature points within a certain window around predicted position on right image were regarded as potential matched points, whereas the same. After feature-to-feature normalized correlation coefficient (NCC) matching under the constraints of the triangulated irregular network was performed, a reasonable NCC threshold was used to remove the mismatched points (Row 3 in Table 1). As a result, the seed points and the matching feature points (Row 6 in Table 1) were the totally corresponding image points in 1st layer (Row 7 in Table 1).

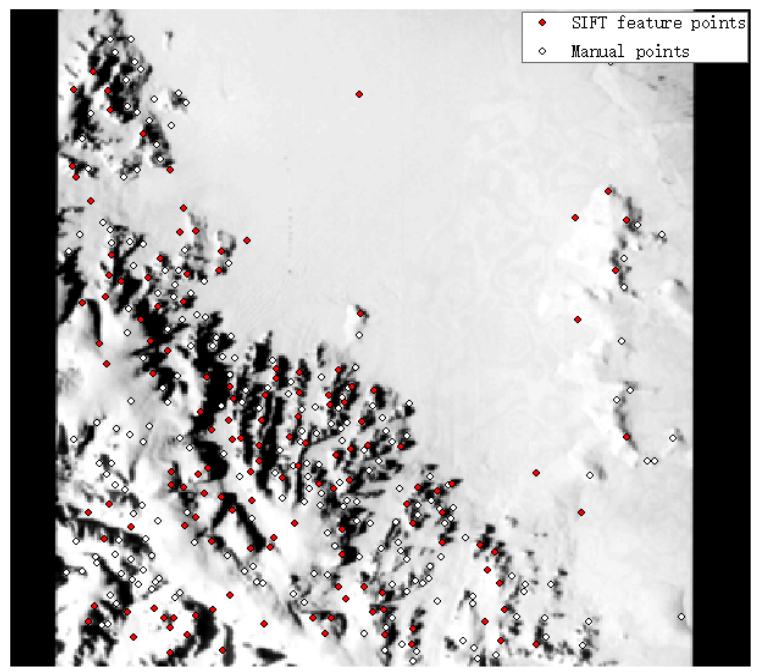

Figure 1. Distribution of SIFT feature points and manual points; red dot indicate SIFT feature points, white dot indicate manual points

3) The matching points were passed from upper layer to next Layer (Row 1 and second to the fifth layer in Table 1). According to the down sampling interval when the pyramid image was created, that one pixel on the higher layer was divided into four pixels on the next layer. So the coordinates of the matching point should multiply two when passed the matching points from upper layer to next layer. When one match point transmitted to the next level, four points that divided from passed right matching point were potential corresponding points of passed left matching points, so it is necessary to find the unique corresponding points of the left match point by re-matching.

4) The refined matching points can be as the seed points in this layer to generate a triangulated irregular network in both images respectively. Repeat step 2 and 3 until the match points were passed to the original resolution image.

\begin{tabular}{|c|c|c|c|c|c|c|c|}
\hline \multirow{2}{*}{ Row } & \multirow{2}{*}{ Image Matching Step } & $1^{\text {st }}$ layer & $2^{\text {nd }}$ layer & $3^{\text {rd }}$ layer & $4^{\text {th }}$ layer & $5^{\text {th }}$ layer & $6^{\text {th }}$ layer \\
\hline & & (Scale 1/16) & (Scale 1/8) & $($ Scale $1 / 4)$ & $($ Scale $1 / 2)$ & (Scale 1) & (Scale 1, grid) \\
\hline \multirow{2}{*}{1} & \multirow{2}{*}{$\begin{array}{c}\text { Rematched features from }(\mathrm{n}-1)^{\mathrm{th}} \\
\text { layer }\end{array}$} & \multirow{2}{*}{360} & 698 & 2423 & 8094 & 25929 & \multirow{2}{*}{ NONE } \\
\hline & & & $94.84 \%$ & $97.39 \%$ & $83.76 \%$ & $66.56 \%$ & \\
\hline 2 & Number of detected features & 562 & 2445 & 15263 & 67993 & 238419 & 1321320 \\
\hline \multirow{2}{*}{3} & \multirow{2}{*}{$\begin{array}{l}\text { Number of initial matched } \\
\text { features by NCC correlation }\end{array}$} & 485 & 2162 & 8425 & 33715 & 98361 & 385504 \\
\hline & & $86.30 \%$ & $88.43 \%$ & $55.20 \%$ & $49.59 \%$ & $41.26 \%$ & $29.18 \%$ \\
\hline \multirow{2}{*}{4} & \multirow{2}{*}{$\begin{array}{c}\text { Number of eliminated features } \\
\text { by parallax constraint }\end{array}$} & 54 & 259 & 521 & 2853 & 17788 & 47592 \\
\hline & & $11.13 \%$ & $11.98 \%$ & $6.18 \%$ & $8.46 \%$ & $18.08 \%$ & $12.35 \%$ \\
\hline \multirow{2}{*}{5} & \multirow{2}{*}{$\begin{array}{c}\text { Number of eliminated features } \\
\text { by surface fitting constraint }\end{array}$} & 55 & 372 & 570 & 3001 & 6480 & 14717 \\
\hline & & $11.34 \%$ & $17.21 \%$ & $6.77 \%$ & $8.90 \%$ & $6.59 \%$ & $3.82 \%$ \\
\hline 6 & $\begin{array}{l}\text { Newly confirmed matched } \\
\text { features at nth layer }\end{array}$ & 376 & 1790 & 7240 & 30862 & 74092 & 323195 \\
\hline 7 & $\begin{array}{c}\text { Total number of features at } \mathrm{n}^{\text {th }} \\
\text { layer (Row } 1+\text { Row } 6 \text { ) }\end{array}$ & 736 & 2488 & 9663 & 38956 & 100021 & 423216 \\
\hline
\end{tabular}

Table 1. Matching and eliminated points for each layers in details 
5) Finally, dense matching in original resolution image was applied to very five-pixel grid.

The matching points in each layer and eliminated points by NCC threshold, parallax constraint (Row 4 in Table 1) and surface fitting constraint (Row 5 in Table 1) are shown in Table 1.

\subsection{Bundle Adjustment}

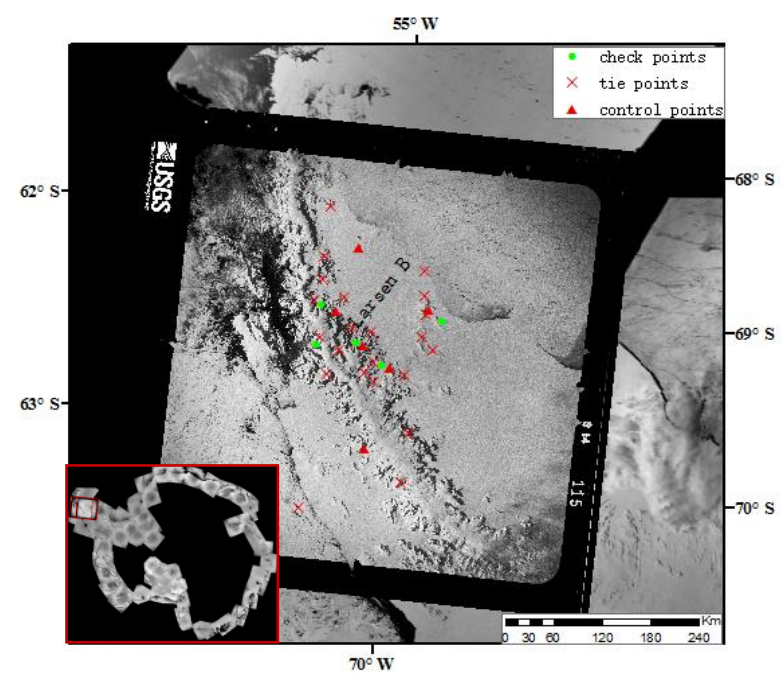

Figure 2. The location of Larsen B with an ARGON mosaic as background (Kim et al. 2007). And the distribution of tie points, ground control points and check points

In order to project the matching point to the object coordinate system, it is necessary to calculate the exterior orientation element of images. In this paper, Bundle adjustment (BA) was performed to calculate the exterior orientation element of ARGON images using the commercial software (ERDAS, 2013) LPS of Leica Systems. In this paper we use two ARGON stereo images covering the Larsen B ice shelf. Figure 2 shows the coverage of two ARGON images. 22 tie points, 6 ground control points (GCPs) were involved in the bundle adjustment process (Figure 2). The GCPs obtained from LIMA and ASTER DEM, in order to get a good geometry to avoid unpredictable distortion, it is necessary to make sure the distribution of the tie points is balance in the overlapping area. The internal and external accuracy of BA results was evaluated using the tie points and check points, respectively. The result show that the bundle adjustment of the Larsen B yielded a unit-weight RMSE of 0.52 pixels, this indicated a high level of internal accuracy of the BA. With the geometric positioning parameters obtained from the BA, 5 check points were calculated to assess the external accuracy of the BA. The check points were calculated from BA is compare to the coordinate measured in the LIMA mosaic (Bindschadler, $\mathrm{R}$. et al., 2008) and the ASTER GDEM (Tachikawa, T. et al., 2011). The differences between BA and known coordinates were used to evaluate external accuracy shown in Table 2 . We can see both horizontal accuracy and vertical accuracy are within one nominal pixel of $140 \mathrm{~m}$.

\begin{tabular}{c|c|c|c}
\hline RMSE & $\Delta \mathbf{X}(\mathbf{m})$ & $\Delta \mathbf{Y}(\mathbf{m})$ & $\Delta \mathbf{Z}(\mathbf{m})$ \\
\hline Value & 63 & 43 & 48 \\
\hline
\end{tabular}

Table 2. The external accuracy of Larsen B BA estimated by check points

\subsection{Larsen B DEM Reconstruction}

The matching points were projected onto the world coordinate system using the parameters obtained from the BA. According to the density of the point a $300 \mathrm{~m}$ resolution DEM was produced. A $3 \mathrm{D}$ view of the ARGON image draped on the DEM shows in Figure 3.

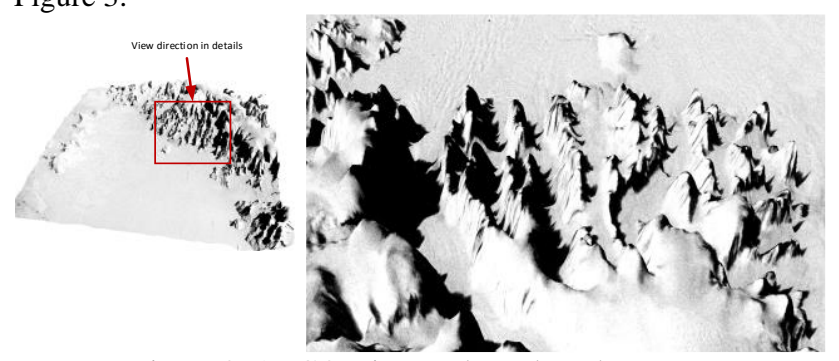

Figure 3. ARGON image draped on the DEM

\section{EVALUATION OF MATCHED POINTS}
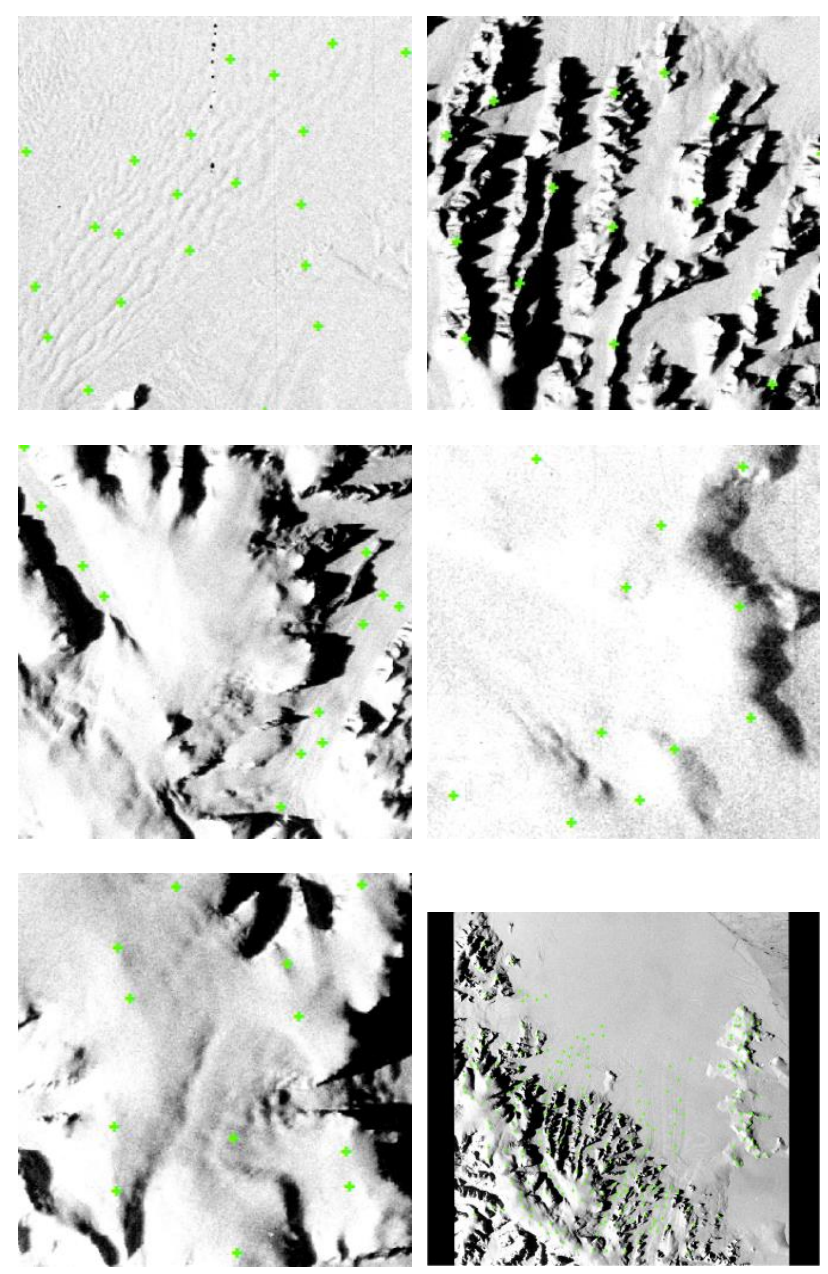

Figure. 4. Distribution of check points over five test regions and entire region

Matched points are evaluated at each level were by selecting manual points. Here automatically matched points compared with the manually check points (CPs) in the image space to calculate the point distances represent matching residuals ( $\mathrm{Li}$ et al. 2011). Grid was drawn according to the image scale at each level and no more than one point in one cell when select CPs. 50 random CPs were manually matched throughout the entire study 
area at levels 1-5. The final level (level 6th) is 5-pixels grid level. Combined with the terrain features and research interests of Larsen B, five region with various terrain types were selected and 50 CPs were derived for each one. Region 1 has ice streams with slight motion. The density of points is larger than others since ice stream areas are relative small. Region 2 is the summit in Larsen $\mathrm{B}$ region where surface texture is sufficient, exhibiting the best matching results with smallest mean residual of 0.18 pixel. Region 3 is a region with valleys produced the higher mean residual of 0.49 pixel caused by large shadows and lack of detailed texture. Region 4 is the Jason Peninsula with smooth and bright surface and the features matched not very well, either, with a mean residual of 0.61 pixel. Region 5 in ridge area shows the similar mean residual to region 4 .

The smallest mean residuals just 0.18 pixel and the largest is 0.32 pixel within 3 times the standard deviation. Thus, the evaluation of matched points is acceptable (Table 3 ).

Some of the feature names aforementioned are unofficial.

\begin{tabular}{|c|c|c|c|c|c|}
\hline \multirow[b]{2}{*}{ Poin } & \multirow[b]{2}{*}{ Type } & \multirow{2}{*}{$\begin{array}{l}\text { Number } \\
\text { of Points }\end{array}$} & \multicolumn{3}{|c|}{ Residuals(Pixel) } \\
\hline & & & Mean & $\begin{array}{l}\text { Standard } \\
\text { Deviation }\end{array}$ & $\operatorname{Max}$ \\
\hline \multirow{5}{*}{$\begin{array}{c}\text { Matched } \\
\text { Point }\end{array}$} & Level1 & 50 & 0.31 & 0.18 & 0.68 \\
\hline & Level2 & 50 & 0.32 & 0.16 & 0.63 \\
\hline & Level3 & 50 & 0.49 & 0.28 & 1.14 \\
\hline & Level4 & 50 & 0.52 & 0.29 & 1.30 \\
\hline & Level5 & 50 & 0.55 & 0.30 & 1.39 \\
\hline \multirow{5}{*}{$\begin{array}{l}\text { Grid } \\
\text { point }\end{array}$} & $\begin{array}{c}\text { Ice } \\
\text { stream }\end{array}$ & 50 & 0.42 & 0.19 & 0.79 \\
\hline & Summit & 50 & 0.41 & 0.18 & 0.79 \\
\hline & Valley & 50 & 0.49 & 0.32 & 1.39 \\
\hline & Ridge & 50 & 0.61 & 0.27 & 1.30 \\
\hline & Peninsula & 50 & 0.62 & 0.30 & 1.29 \\
\hline
\end{tabular}

Table 3. Matching Residuals at 6 Levels

\section{FUTURE WORK}

Next, comparison between ARGON DEM of Larsen B region, derived from an 1963 ARGON stereo image pair and observations from different satellites in several periods will be conducted .The difference with satellite altimetry data of ERS and ICESat will be used to analyze the elevation changes of Larsen B ice shelf in past several decades; comparison with Digital Elevation Model such as ASTER DEM and SPOT DEM can reveal the elevation changes of Larsen B tributary glaciers between the pre- and post-collapse.

\section{FUNDING}

This research was supported by the National Basic Research Program of China-973 program (2012CB957701), and National Natural Science Foundation of China (41201471).

\section{REFERENCES}

Berthier, E., Scambos, T. A., Shuman, C. A., 2012. Mass loss of Larsen B tributary glaciers (Antarctic Peninsula) unabated since 2002. Geophysical Research Letters, 39(13).
Bindschadler R., Vornberger P., Fleming A., Fox A., Mullins J., Binnie D., Paulsen S.J., Granneman B., Gorodetzky D., 2008. The Landsat image mosaic of Antarctica. Remote Sensing of Environment, 112(12), 4214-4226.

Cook, A. J., Vaughan, D. G., 2010. Overview of areal changes of the ice shelves on the Antarctic Peninsula over the past 50 years. The Cryosphere, 4(1), 77-98.

Fricker, H. A., Padman, L., 2012. Thirty years of elevation change on Antarctic Peninsula ice shelves from multimission satellite radar altimetry. Journal of Geophysical Research: Oceans, 117(C2).

Hartley, R., Zisserman, A., 2003. Multiple view geometry in computer vision. Cambridge university press.

Helava, U. V., Chapelle, W. E., 1972. Epipolar-scan correlation. Bendix Technical Journal, 5(1), 19-23.

Khazendar, A., Borstad, C. P., Scheuchl, B., Rignot, E., Seroussi, H., 2015. The evolving instability of the remnant Larsen B Ice Shelf and its tributary glaciers. Earth and Planetary Science Letters, 419, 199-210.

Kim, K., Jezek, K. C., Liu, H., 2007. Orthorectified image mosaic of Antarctica from 1963 Argon satellite photography: image processing and glaciological applications. International Journal of Remote Sensing, 28(23), 5357-5373.

Li, R., Hwangbo, J., Chen, Y., Di, K., 2011. Rigorous photogrammetric processing of HiRISE stereo imagery for Mars topographic mapping. IEEE Transactions on Geoscience and Remote Sensing, 49(7), 2558-2572.

Li, R., Ye, W., Qiao, G., Tong, X., Liu, S., Kong, F., Ma, X., 2017. A New Analytical Method for Estimating Antarctic Ice Flow in the 1960s From Historical Optical Satellite Imagery. IEEE Transactions on Geoscience and Remote Sensing, 55(5), 2771-2785.

Lowe, D. G., 1999. Object recognition from local scale-invariant features. In Computer vision, 1999. The proceedings of the seventh IEEE international conference on (Vol. 2, pp. 11501157). Ieee.

Rack, W., Rott, H., 2004. Pattern of retreat and disintegration of the Larsen B ice shelf, Antarctic Peninsula. Annals of Glaciology, 39(1), 505-510.

Rignot, E., Casassa, G., Gogineni, P., Krabill, W., Rivera, A. U., \& Thomas, R., 2004. Accelerated ice discharge from the Antarctic Peninsula following the collapse of Larsen B ice shelf. Geophysical Research Letters, 31(18).

Rott, H., Müller, F., Nagler, T., \& Floricioiu, D., 2011. The imbalance of glaciers after disintegration of Larsen-B ice shelf, Antarctic Peninsula. The Cryosphere, 5(1), 125.

Shepherd, A., Wingham, D., Payne, T., \& Skvarca, P., 2003. Larsen ice shelf has progressively thinned. Science, 302(5646), 856-859.

Shi, J., 1994. Good features to track. In Computer Vision and Pattern Recognition, 1994. Proceedings CVPR' 94. 1994 IEEE Computer Society Conference on (pp. 593-600). IEEE. 
Shuman, C. A., Berthier, E., \& Scambos, T. A., 2011. 2001-2009 elevation and mass losses in the Larsen A and B embayments, Antarctic Peninsula. Journal of Glaciology, 57(204), 737-754.

Skvarca, P., Rack, W., Rott, H., 1999. 34 year satellite time series to monitor characteristics, extent and dynamics of Larsen B Ice Shelf, Antarctic Peninsula. Annals of Glaciology, 29(1), 255- 260.

Tachikawa, T., Hato, M., Kaku, M., Iwasaki, A., 2011. Characteristics of ASTER GDEM version 2. In Geoscience and Remote Sensing Symposium (IGARSS), 2011 IEEE International (pp. 3657-3660). IEEE.

Vaughan, D. G., Doake, C. S. M., 1996. Recent atmospheric warming and retreat of ice shelves on the Antarctic Peninsula. Nature, 379(6563), 328.

Wuite, J., Rott, H., Hetzenecker, M., Floricioiu, D., De Rydt, J., Gudmundsson, G. H., Nagler, T., Kern, M., 2015. Evolution of surface velocities and ice discharge of Larsen B outlet glaciers from 1995 to 2013. The Cryosphere, 9, 957-969.

Cole S., Buis A., 2015. NASA Study Shows Antarctica's Larsen B Ice Shelf Nearing Its Final Act. https://www.nasa.gov/pressrelease/nasa-study-shows-antarctica-s-larsen-b-ice-shelfnearing-its-final-act (accessed on 27 April 2017). 